framum

Sociológico

\section{Forum Sociológico}

Série II

$29 \mid 2016$

Número 29

\title{
As escolas privadas e os seus clientes : estratégias organizacionais de promoção da oferta e de regulação das admissões
}

Private schools and their customers: organizational strategies for promoting supply and regulating admissions

Jorge Ávila de Lima e André Costa Melo

\section{OpenEdition}

Journals

Edição electrónica

URL: https://journals.openedition.org/sociologico/1514

DOI: 10.4000/sociologico.1514

ISSN: 2182-7427

Editora

CICS.NOVA - Centro Interdisciplinar de Ciências Sociais da Universidade Nova de Lisboa

\section{Refêrencia eletrónica}

Jorge Ávila de Lima e André Costa Melo, «As escolas privadas e os seus clientes : estratégias organizacionais de promoção da oferta e de regulação das admissões», Forum Sociológico [Online], 29 | 2016, posto online no dia 31 dezembro 2016, consultado o 29 março 2022. URL: http:// journals.openedition.org/sociologico/1514 ; DOl: https://doi.org/10.4000/sociologico.1514 


\title{
AS ESCOLAS PRIVADAS E OS SEUS CLIENTES: ESTRATÉGIAS ORGANIZACIONAIS DE PROMOÇÃO DA OFERTA E DE REGULAÇÃO DAS ADMISSÕES \\ PRIVATE SCHOOLS AND THEIR CUSTOMERS: ORGANIZATIONAL STRATEGIES FOR PROMOTING SUPPLY AND REGULATING ADMISSIONS
}

\author{
Jorge Ávila de Lima \\ Universidade dos Açores, Faculdade de Ciências Sociais e Humanas, Departamento de Sociologia \& Centro Interdisciplinar \\ de Ciências Sociais (CICS.NOVA.UAçores)
}

\section{André Costa Melo}

Escola Básica e Integrada de Rabo de Peixe, Núcleo de Educação Especial

\begin{abstract}
Resumo
Conhece-se ainda pouco sobre o modo como as organizações escolares privadas promovem a sua oferta junto dos potenciais clientes e como regulam a procura de que são objeto por parte das famílias. O presente artigo apresenta os resultados de um estudo de caso exploratório que investigou estas questões em duas escolas privadas com oferta formativa ao nível do $1^{\circ}$ Ciclo do Ensino Básico. Os dados foram recolhidos através de entrevistas exploratórias realizadas aos diretores das escolas e a docentes de ambas. Os resultados mostram que as organizações estudadas procuram diferenciar-se das concorrentes através da criação e promoção de uma imagem de marca junto dos seus públicos e que regulam a procura de que são objeto através da utilização de estratégias seletivas de definição de perfis preferenciais de alunos a admitir.
\end{abstract}

Palavras-chave: escolas privadas, diferenciação de mercado, marketing da escola, estratégias organizacionais

\begin{abstract}
Little is still known about how school organizations promote their educational supply to potential customers and how they regulate demand from families. This paper presents an exploratory study that addressed these questions. The research took place in two private schools that offer education at the elementary level. The data was collected through exploratory interviews with school principals and teaching staff. The results show that the organizations attempt to differentiate themselves in the market by constructing a brand image of themselves and that they use selective admission strategies by defining preferential student profiles.
\end{abstract}

Keywords: private schools, market differentiation, school marketing, organizational strategies

\section{Introdução}

As escolas privadas são "estabelecimentos de ensino pertencentes a entidades do setor privado ou cooperativo" (Cotovio, 2004: 22) nos quais tanto a propriedade como a gestão são da responsabilidade de entidades não estatais. Estas escolas têm sido, ultimamente, alvo de bastante atenção por parte dos meios de comunicação social, da opinião pública e dos políticos, a nível nacional e internacional. Nas últimas décadas, têm sido muitos os trabalhos científicos realizados sobre a matéria, especialmente no estrangeiro. Em Portugal, o tema também tem sido estudado, embora de forma menos sistemática (cf. Abrantes e Quaresma, 2013; Cotovio, 2004; Estêvão, 1998; 2000; Quaresma, 2014). Sabemos 
ainda pouco, por exemplo, sobre o modo como as escolas privadas portuguesas funcionam enquanto organizações, de que forma lidam com as suas clientelas e que processos utilizam para assegurar a cativação ou retenção de alunos.

Num mundo em que os sistemas educativos estão cada vez mais liberalizados e globalizados (Laval, 2003; Lima e Afonso, 2002), a regulação da educação pelo mercado conduz frequentemente a uma competição entre organizações escolares (Barroso, 2005). Este contexto propiciou a criação de novas estruturas e formas de comunicação para mediar a relação das escolas com as suas "clientelas" (Bagley et al., 1996). Especialmente nos sistemas educativos em que foi introduzida a liberalização da escolha do estabelecimento de ensino pelas famílias e a consequente competição entre organizações escolares, quer dentro de cada setor (público e privado), quer entre ambos, tem-se verificado a emergência de um fenómeno novo: o esforço de publicitação, por parte das escolas, das suas qualidades junto da clientela potencial. Por outro lado, há relatos informais, se bem que ainda pouco documentados em pesquisas concretas, de que as próprias escolas adotam procedimentos seletivos no sentido de admitirem sobretudo alunos com um perfil socioeconómico que não comprometa a sua atratividade.

Contudo, as tendências acima descritas podem depender fortemente do nível de procura de que as organizações escolares são objeto. Na verdade, se a forte pressão pela busca de candidatos pode estimular, do lado da oferta, a adoção de comportamentos pró-ativos, se não mesmo agressivos, no mercado educativo; o excesso de procura pode, pelo contrário, relegar o marketing para um lugar secundário e suscitar processos em que é a escola que escolhe os alunos e não estes que a selecionam.

Estes aspetos serão abordados no presente texto, no qual analisaremos o comportamento de duas escolas privadas que, sendo objeto de forte procura por parte das famílias, desenvolveram formas de lidar com tal procura, quer através da gestão da sua imagem e visibilidade no mercado, quer através do modo como arquitetaram o processo de admissão dos alunos que as procuravam.

\section{Estratégias de promoção das escolas}

Se, por um lado, para tomar uma decisão sobre que estabelecimento de ensino escolher, os pais sentem a necessidade de formar uma imagem sobre cada um desses estabelecimentos; por outro, estes, especialmente em ambientes de concorrência potencial entre escolas, quer públicas, quer privadas, têm consciência destes processos e da sua importância e procuram interferir na formação das perceções dos seus clientes potenciais, esforçando-se por construir e promover uma certa imagem de marca.
Neste processo, temos vindo a assistir a uma crescente penetração da linguagem e dos valores comerciais, quer nas escolas privadas, quer nas públicas. Referindo-se à realidade norte-americana, onde esta tendência atinge graus de profundidade significativos, Molnar (2006) salientou a emergência do marketing das escolas - a gestão das escolas, mesmo as públicas, ao estilo empresarial, agindo de modo concorrencial, atuando no mercado na disputa de alunos e procurando que os seus "produtos" sejam "comprados" pelos "clientes". A este respeito, Laval (2003: 131), aludindo à ação das escolas enquanto atores que agem num mercado, menciona o fenómeno da mercantilização, não só dos produtos educativos oferecidos, mas da própria escola, entrando num mercado concorrencial para disputar clientes. Nalguns contextos nacionais onde a introdução de políticas educativas neoliberais foi mais pronunciada, o marketing às famílias ganhou uma prioridade forte na agenda das escolas, ao ponto de existir já, na área da gestão escolar, uma literatura dedicada exclusivamente a este tópico (Banach, 2001; Lockhart, 2005; Warner, 2009).

Num contexto de competição por clientes, mesmo que mitigada (como é o caso de Portugal ver Afonso, 2002), as escolas podem desenvolver estratégias de diferenciação, procurando identificar e, posteriormente, oferecer o que os consumidores desejam (ou aquilo que é possível persuadi-los a adquirirem). Glatter et al. (1997) referem sete tipos de diferenciação possíveis num mercado educativo (Quadro 1).

Do ponto de vista de Bagley et al. (1996: 127), "para que o marketing seja eficaz, as escolas precisam de ter uma visão clara do que os pais pensam, como tomam decisões e o que procuram numa escola. Também exige que as escolas tenham meios eficazes de agir com base neste conhecimento e compreensão." Num estudo realizado em 11 escolas inglesas do Ensino Secundário, os autores acima mencionados recolheram informação sobre a condução (ou não), pelas escolas, de atividades que visam conhecer melhor o seu meio envolvente, em particular as perspetivas dos pais. Com base neste modelo, os autores distinguiram dois tipos de informação recolhidos pelas organizações escolares: o feedback sistemático e planeado, e o feedback ad hoc.

No primeiro caso, o estudo identificou as seguintes modalidades: inquéritos por questionário aos pais; utilização de formulários com questionamento das razões da escolha dos pais, aquando da matrícula dos filhos no estabelecimento de ensino; utilização de dados secundários obtidos a partir de inquéritos; exercícios de brainstorming realizados na própria escola para identificar os seus pontos fortes e fracos; monitorização seletiva das origens dos alunos em termos das escolas primárias de que 
Quadro $1 \triangleright$ Tipos de diferenciação de oferta da escola

\begin{tabular}{|c|c|}
\hline Tipo & Descrição \\
\hline Estrutural & Formas organizacionais distintas de governação, financiamento e propriedade \\
\hline Curricular & $\begin{array}{l}\text { Domínios em que as escolas se especializam ou aspetos particulares do currículo } \\
\text { que enfatizam }\end{array}$ \\
\hline Estilo & $\begin{array}{l}\text { Énfase num estilo de ensino e/ou de aprendizagem particular ou numa determinada } \\
\text { abordagem educativa }\end{array}$ \\
\hline Religiosa/filosófica & $\begin{array}{l}\text { Promoção ou aposta num sistema de crenças religiosas particular ou numa } \\
\text { filosofia política }\end{array}$ \\
\hline Género & $\begin{array}{l}\text { Variações entre escolas quanto ao género dos alunos (masculinas, femininas, } \\
\text { mistas ou híbridas) }\end{array}$ \\
\hline Especialização de mercado & $\begin{array}{l}\text { Orientação para a atração de pessoas de um segmento ou segmentos específicos } \\
\text { do mercado }\end{array}$ \\
\hline Amplitude de idades & Variação segundo a amplitude de idades dos alunos \\
\hline
\end{tabular}

são oriundos, tendo em vista atrair os alunos das escolas primárias que os preparam melhor, sendo a atividade promocional da escola, depois, dirigida principalmente para esses estabelecimentos de ensino; monitorização dos registos de batismo e do número de alunos nas escolas primárias, quando o estabelecimento de ensino se preocupa, por exemplo, em atrair alunos de famílias católicas.

Quanto ao feedback ad hoc, trata-se de uma recolha informal de informação que ocorre nas escolas, muitas vezes em resultado de encontros casuais com pais ou outros elementos da comunidade (por exemplo, os professores das escolas primárias de onde os alunos são oriundos) ou de contatos realizados por iniciativa das famílias. Este tipo de feedback obtém-se, frequentemente no decurso de iniciativas organizadas para outros fins, como dias abertos, visitas a escolas primárias para promover o estabelecimento de ensino e contatos com as associações de pais.

No seu estudo, os autores mostraram que o "scanning e interpretação" dos pontos de vista dos pais não eram uma atividade que recebesse uma prioridade elevada na maioria das escolas estudadas. Houve escolas em que os professores e diretores se mostraram mais recetivos às perspetivas de alguns pais, mas não às de outros: a sua propensão para agirem em função do que os pais pensavam era maior quando estes últimos eram de classe média ou média-alta e tinham filhos com um bom percurso académico - exatamente o tipo de pais e de alunos que estas escolas queriam atrair. No estudo, também ficou claro que o marketing da escola não é uma mera atividade de informação, pois pode envolver igualmente a persuasão - por exemplo, um diretor entrevistado pelos autores afirmou: "falamos com os nossos pais e procuramos convencê-los de que é isso que eles querem ... as pessoas são maleáveis. Se tens um produto para vender, podes moldar as pessoas de modo a que o aceitem" (citado por Bagley et al., 1996: 133). Resultados semelhantes foram obtidos numa investigação realizada por Levin e Riffel (1997).

\section{Regulação das admissões de alunos por parte das escolas}

Existem muitas práticas que as organizações escolares podem usar para regular a procura de que são alvo por parte das famílias. Um aspeto particularmente importante desta gestão são as políticas de admissão de alunos, que podem assumir diversas formas. West e Pennell (1997) referiram, entre outras, as seguintes:

a) perfil preferencial - seleção de todos os alunos de acordo com um critério ou conjunto de critérios fixos (por exemplo, ter irmãos na escola, ter necessidades médicas ou sociais especiais, ou ser da zona geográfica da escola);

b) seleção encoberta - funciona quando não existem mecanismos externos de prestação de contas que procurem perceber se a escola está ou não a admitir adequadamente os seus alunos, em obediência a critérios de justiça e equidade. Geralmente, faz-se através da realização de uma entrevista prévia com os pais e/ou o candidato a aluno, em que se dá particular importância às características deste último e da família - por exemplo, a sua orientação religiosa, os valores dominantes, etc. Outra modalidade é a conceção deliberada de um formulário de candidatura tão longo e complexo que os pais com menor nível de escolaridade não conseguem preenchê-lo devidamente, sendo por isso excluídos. 
Alguns tipos de alunos são olhados negativamente por uma boa parte das escolas, que preferem não os ter nas suas fileiras. Numa situação de mercado, esta situação pode agudizar-se. Comentando a investigação sobre a escolha da escola, que tem incidido sobre múltiplas realidades nacionais, envolvendo quer escolas privadas, quer também, nalguns contextos, escolas públicas, Barroso (2003: 104-105) recorda que aquela demonstra a existência de fenómenos sistemáticos e consistentes de segregação, gerados por processos "informais", não só de escolha da escola pelos pais, mas também de seleção dos alunos pelas escolas. Dale (1996: 126) também chama a atenção para esta dimensão-chave da competição e escolha nos mercados educacionais: é que nestes, "diversamente do mercado clássico, nem todos os clientes são de igual valor; na verdade, alguns são de valor negativo", o que significa que "as escolas, numa situação de mercado competitivo, são suscetíveis de competir não apenas para poder aceitar algumas categorias de alunos, mas também para rejeitar outras" (Dale, 1996: 128).

\section{Estudo empírico}

Tendo em conta a problemática discutida anteriormente, o estudo empírico que relatamos no presente texto procurou responder a duas questões de pesquisa principais: (1) Que estratégias utilizam as escolas privadas para atraírem a atenção dos pais na decisão da escolha da escola? (2) De que modo gerem estas escolas a admissão dos alunos que a elas se candidatam?

Para obter informação sobre esta questões, foi desenhado um estudo de caso que incidiu sobre duas escolas privadas que ministravam ensino do $1^{\circ}$ Ciclo do Ensino Básico num concelho português. A Escola 1 tem aproximadamente centena e meia de alunos, dos quais cerca de $65 \%$ estão matriculados no $1^{\circ}$ Ciclo do Ensino Básico, enquanto a Escola 2 tem aproximadamente 600 alunos, com cerca de $70 \%$ no $1{ }^{\circ}$ Ciclo. A primeira escola tem um corpo docente de perto de 10 elementos, enquanto a segunda emprega cerca de quatro dezenas ${ }^{1}$.

Optou-se por inquirir, em cada escola, através de entrevistas exploratórias, com algum grau de estruturação, a diretora e duas docentes, num total de seis entrevistas. Ambas as diretoras entrevistadas têm formação de base na área do Ensino Básico 10 Ciclo. Ambas tiveram experiência de lecionação, durante vários anos, em escolas públicas, tendo sido depois, inicialmente, professoras em escolas privadas. Posteriormente, assumiram cargos de direção nas suas escolas. Quanto às docentes entrevistadas, são todas licenciadas em Ensino Básico - 1.0 Ciclo. À exceção de uma, que sempre trabalhou em escolas privadas, as restantes trabalharam primeiro no setor público. Os anos de serviço das entrevistadas variam entre os 9 e os 30. A opção por entrevistar estes dois tipos de participantes teve por base o desejo de obter pontos de vista eventualmente diferenciados sobre as escolas estudadas, quer a partir das posições de liderança, quer das de execução técnica, embora posteriormente, após a recolha e análise dos dados, tenhamos constatado a inexistência de diferenças de perspetiva significativas entre ambos os grupos de participantes.

O estudo baseou-se numa abordagem exploratória qualitativa, atenta ao detalhe, sem propósitos de generalização. As entrevistas, complementadas com a análise de material documental produzido pelas próprias escolas (Projetos Educativos, Planos de Atividades, Regulamentos Internos), visaram perceber a forma como estas procuravam cativar "clientes" e como regulavam a procura de que eram objeto por parte das famílias, particularmente ao nível das admissões. No primeiro caso, deu-se atenção especial às estratégias de promoção da escola, em dimensões como as áreas de formação e serviços escolhidos e divulgados pela escola, a marketing e a gestão das infraestruturas físicas e recursos humanos. A análise da regulação organizacional da procura incidiu sobretudo sobre os critérios de escolha dos alunos, aplicados pela escola. Os dados foram submetidos a uma análise de conteúdo de caráter temático, que incidiu sobre duas categorias principais: formas de promoção da escola e modos de regulação da procura.

Para as entrevistas, foi elaborado um protocolo de consentimento informado, que foi assinado pelo investigador e por cada uma das participantes. Para preservar a confidencialidade dos dados, foi atribuído a cada escola um código numérico. Nos excertos de entrevista que apresentaremos, usamos a letra D para identificar testemunhos de diretores e o P para relatos de professores. Os códigos 1 e 2 referem-se às escolas.

\section{Resultados}

Estratégias usadas pelas escolas privadas para atraírem a atenção dos pais na decisão da escolha do estabelecimento de ensino

As escolas estudadas preocupavam-se em apresentar às famílias um tipo de oferta que as tornasse atrativas, apostando na diferenciação no mercado (Glatter et al., 1997). Por exemplo, ofereciam atividades extracurriculares, após o fim do horário letivo (o que permitia o alargamento do horário até às 18 horas), que eram potencialmente atrativas para as famílias. Por exemplo, a escola 1 oferecia atividades de xadrez, violão, hip-hop, ballet, informática, ginástica, salas de estudo e modalidades de escolinhas do desporto; e a escola 
2 oferecia ballet, "ciência divertida", computadores, futebol, inglês, judo, patinagem, oficina da matemática, xadrez, ténis, badmington, grupo ORFF, dança moderna e grupo coral.

Outra estratégia de diferenciação utilizada por ambas as escolas para atrair a atenção dos pais era a forma particular como cada uma realizava a gestão dos seus recursos físicos e humanos. Por exemplo, a escola 1 procurou dotar-se de material informático inexistente noutras instituições, para assim cativar a atenção dos seus alunos e respetivas famílias. A diretora da escola, ciente de que a estrutura física do seu edifício não era apelativa para a escolha dos pais, também procurava compensar esta debilidade com a publicitação da qualidade dos seus funcionários (competência, assiduidade, empenhamento):

"os professores raramente faltam ... não enganam a diretora, são muito francos (...). Nós temos às vezes reuniões à noite, nós trabalhamos às vezes ao sábado para festas e cenários e coisas no género, [e] ninguém me vem pedir acréscimo no ordenado." (D1)

Por seu lado, a diretora da escola 2 apostava na propagação de ideia de que na sua escola, comparativamente com as públicas, havia mais segurança para os alunos e uma formação académica mais consistente e exigente.

"Os pais dizem também que a segurança ... não é? Sabem que, realmente, associada aos valores, ao espaço e ao horário ... os meninos estão seguros e [os pais] estão descansados. (...) Até me dizem e pedem muito, a maioria dos pais pedem muito que ... se construíssemos [uma extensão da escola], a ver se conseguimos abranger até ao $6 .^{\circ}$ ano, não é? É uma das coisas que nos pedem muito, porque dizem que realmente os filhos vão lá para fora, é como [se fossem] para a selva, não é?! (...) É que os alunos realmente aqui são mais protegidos, não é? Têm outra ... outro ... outra maneira de ser e contam-nos ... os próprios [antigos] alunos, às vezes vêm cá e contam-nos o que se passa nas salas [das escolas públicas], não é?! A educação ... se nós às vezes nos queixamos de falta de disciplina, então eles lá no [público] é pior, não é!? Eles não consideram isso normal e dizem que aquilo comparado com aqui parecia uma selva." (D2)

Este ponto de vista foi reforçado pelas docentes entrevistadas na escola:

"Eu já há muito tempo que não estou em contato com o ensino público, não é? Mas daquilo que tenho ouvido ... portanto, é que continua a exigir-se muito pouco a nível das aprendizagens das crianças. Facilitismo, há muito facilitismo. Aqui ... pelo contrário, aqui, ou em qualquer [escola privada], não é [assim]. Uma vez que os pais estão a pagar, eu julgo que as direções [das escolas privadas] exigem dos professores [que] trabalhem [e] (...) os professores são obrigados a exigir dos alunos também." (P2)

As entrevistadas, quer diretoras, quer professoras, também acentuaram o fato de as suas escolas se distinguirem por terem uma grande competência para formar cidadãos:

"Eu acho que, apesar de [esta escola] não ser uma escola de cunho católico, (...) todas as pessoas que vivem aqui, que trabalham cá, são pessoas cristãs. Portanto, há um conjunto de valores e de atitudes que nós mostramos bem e que tentamos incutir nas crianças. (...). Será que é por isso só [que os pais escolhem esta escola?]? Eu acho que também é mais uma razão." (P1)

"[Nesta escola] é traçado o que é o perfil do que é ser um bom aluno (o que ajuda os outros, o que brinca nos recreios) e é atribuído um troféu, nominal, está lá o nome do miúdo gravado. Eu acho que isso é lindo, é valorizar exatamente aquilo que se trabalha, os valores dos miúdos, quem é amigo ... e os pais ficam satisfeitos. (...) O nosso ... o nosso ... os nossos louros, vamos lá, vão para esse tipo de concurso que é onde é [premiado] o melhor amigo. Eu não vejo ninguém valorizar as crianças por serem melhores amigas: recebem, no final do ano, um diploma porque foram os melhores alunos. E aqui ninguém recebe diplomas por serem os melhores alunos, aqui são dados diplomas, mas, sobretudo, um troféu que é mandado fazer, especificamente para eles, e acho que é exatamente o que o nosso ... o nosso projeto [de] escola [visa] ... que é valorizar os ... tudo o que é valores, tudo os que são valores humanos, cristãos e ... e ecológicos." (D1)

A diretora da escola 2 sublinhou que o projeto educativo da sua instituição é católico e que tem as suas fontes na Bíblia, nos documentos da Igreja, na Declaração dos Direitos Humanos e na dinâmica educativa da própria fundadora. Para esta diretora, este critério tem um peso que deverá ser essencial na decisão de aceitar ou não a inscrição de certas crianças na escola: 
"Nós não queremos cá os pais ... não os queremos cá só porque [a escola] tem bons espaços, só porque tem [um] bom horário. Aqui esta escola, distingue-se ... noutros lados, sei também que têm bons espaços, têm bons horários. Aqui há mais alguma coisa, porque os pais que vêm (...) [só] porque tem bom espaço e isto tudo, não devem ... não devem vir, acho que estão a tirar o lugar aos pais que realmente queiram aproveitar, que queiram mais valores, não é? (...) Porque os pais que não estão virados para valores (...) vão, certamente, (...) dar trabalho, não vão colaborar com o professor, não é? (...) Não estão para acatar valores e não vão tomar parte pelo professor. A linguagem é totalmente diferente, o professor diz uma coisa assim e em casa falam outra linguagem. Isto torna tudo ... dificulta um pouco a aprendizagem, a nossa ... pronto, o nosso projeto. E eu digo claramente: "Isto é assim" ... no final da entrevista [de admissão de alunos, realizada aos pais]: "Esta escola é católica e passa por valores católicos". Portanto, no final, quem quiser, já sabem como é que é. Quem não quiser, por favor, devem optar por outro lado." (D2)

Docentes de ambas as escolas enfatizaram o fato de as escolas privadas terem um horário alargado, uma vez que isso permite aos pais deixarem os meninos de manhã cedo e só os recolherem ao fim do dia, tendo a garantia de que estão seguros e ocupados.

"Eu acho que a (...) diferença está em termos do horário. Abre às 8:00 e fecha às seis e meia. Nas interrupções letivas a escola não fecha, a não ser no mês de agosto e, para além disso, oferece outras atividades extracurriculares." (P1)

Por fim, as entrevistadas afirmaram ser uma vantagem o fato de nas escolas privadas existir um atendimento personalizado aos Encarregados de Educação, uma maior abertura à comunidade e um maior envolvimento dos pais nas atividades letivas:

"Os horários têm de ser... os pais têm de ser mais servidos, não é? Por isso é que puseram [o filho numa escola privada]. Agora, vamos imaginar ... agora a escola fecha às seis e meia ... vamos imaginar que um grupo que se justifique de pais me diga: "Eu precisava que a escola fechasse às sete". Nós passamos a fechar às sete. (...). Portanto, gerimos sempre para bem de uma comunidade, sempre para bem de uma comunidade, é esse o intuito." (D1)
"Eu julgo que a escola continua a dar sempre primazia aos pais, [a atender a] tudo, praticamente, o que os pais dizem... (...) Tanto que medidas ... aquelas medidas tomadas no início do ano, de os pais deixarem os meninos, lá em baixo, na entrada [da escola], acabaram por não vigorar, porque os pais não concordaram." (P2)

Quando questionadas sobre a forma como os pais tomavam conhecimento sobre as condições e funcionamento das escolas, as entrevistadas apontaram preferencialmente para a informação que passava de pais para filhos, entre familiares e amigos. As redes informais desempenhavam, assim, um papel fundamental na disseminação da informação sobre cada escola:

\footnotetext{
"É exatamente através dos antigos alunos, dos amigos, dos familiares, naquelas conversas de reuniões de família, vão dando o seu parecer: "Ah, o meu está ali [na escola] e eu estou bem". (...) Portanto, vão passando a mensagem, acho que é mais por aí, de boca em boca." (D1)
}

"Eu julgo que é através de outros pais que já tiveram os filhos aqui, das escolas do $2^{\circ}$ ciclo, portanto do feedback que [Ihes chega] dos [alunos] do $2 .^{\circ}$ ciclo e até, em muitos casos, de antigos alunos." (P2)

Predominava assim, em ambas as escolas, a utilização do feedback ad hoc (Bagley et al., 1996) - uma recolha informal de informação que ocorre, nos estabelecimentos de ensino ou fora deles, frequentemente no decurso de encontros casuais com pais ou outros elementos da comunidade ou de contatos com a escola desencadeados por iniciativa das próprias famílias.

Embora sondadas por empresas de publicidade, as diretoras de ambas as organizações relataram que têm resistido a tais investidas, por serem objeto de uma procura por parte das famílias muito superior à sua capacidade de oferta de lugares. Em tom de brincadeira, uma delas acrescentou mesmo que pagaria para que ninguém divulgasse a existência da sua escola. No entanto, alertou para o fato de que se, no futuro, começasse a aparecer competição a nível de mercado, então a escola teria de investir em publicidade. A inexistência do marketing devia-se, pois, ao excesso de procura de que as organizações eram objeto e não a qualquer objeção à utilização deste mecanismo promocional por parte das escolas.

"Nunca fizemos isso [usar estratégias de marketing] e aliás quando alguém nos telefona a sugerir, num jornalinho não sei das quantas, e que querem, por exemplo, aumentar o tamanho 
na lista telefónica, eu digo... é assim, à laia de brincadeira, eu pago para ninguém dizer que nós existimos, porque a lista de espera é tão grande, por enquanto ... enquanto não houver competição a nível de mercado, [neste concelho] ... se começar a haver muitas mais escolas com sucesso, claro que nós vamos ter que ... que fazer esta propaganda. Só que eu suponho que não [será necessário], porque, normalmente, os antigos alunos querem que os seus filhos regressem". (D1)

"Não, a escola [não desenvolve estratégias de marketing]... o próprio marketing são os pais, os antigos alunos e as próprias crianças para garantir que as escolas são verdadeiramente inclusivas, integrando alunos de todos os níveis de aptidão e oriundos de todos os grupos sociais, em vez de serem dominadas pelas famílias cujos recursos Ihes permitem viver perto das organizações mais desejadas e aí inscrever os seus filhos.

Contrariamente aos exemplos acima mencionados, as escolas por nós estudadas efetuavam uma seleção baseada em critérios que davam prioridade a determinados alunos, como podemos ver no Quadro 2. Estes dados mostram que as políticas de admissão destes estabelecimentos de ensino se baseavam na definição de perfis preferenciais que permitiam a realização de uma seleção encoberta (West e Pennell, 1997).

Quadro $2 \triangleright$ Critérios de seleção dos alunos pelas escolas, por ordem de prioridade

\begin{tabular}{l|l}
\multicolumn{1}{c}{ Escola 1 } & \multicolumn{1}{c}{ Escola 2} \\
\hline Irmãos dos alunos que já estão matriculados; & Irmãos dos alunos que já estão matriculados; \\
Filhos dos funcionários; & $\begin{array}{l}\text { Meninos que são mais velhos; } \\
\text { Filhos dos antigos alunos }\end{array}$ \\
Ordem de inscrição & $\begin{array}{l}\text { Filhos dos antigos alunos, desde que tenham colabo- } \\
\text { rado com a escola. }\end{array}$ \\
\hline
\end{tabular}

que depois vão lá para fora. (...) Ainda no outro dia ligaram-me (...) ... pronto, queriam que nós déssemos a conhecer [a escola], pronto ... que fizéssemos marketing, não é? Para os pais conhecerem [a nossa escola], para [a] escolher para os alunos. Não. (...) neste momento, nós não estamos interessados em fazer propaganda, não estou interessada (...) porque o verdadeiro [marketing] é o nosso testemunho, não é? o produto que sai, que vai, é que ... pronto, ali é que realmente as pessoas veem o que [nós fazemos]." (D2)

Modos de regulação da admissão de alunos

Segundo os relatos das diretoras e das docentes, todos os anos existia nestas escolas uma lista de crianças candidatas à admissão que excedia em muito o número de alunos que cada uma delas conseguia acolher.

Num verdadeiro mercado educativo com escoIha totalmente livre e igualdade de probabilidade de ingresso para todos, um mecanismo de ingresso passível de ser utilizado em situações deste tipo (excesso de candidatos) seria a realização, por cada escola, de uma tiragem aleatória, processo que está em vigor, pelo menos de forma parcial, em vários países e que é designado de "admissões por lotaria" (Dolle e Newmann, 2008; Eckes e Trotter, 2007; Moore, 2009; Stasz e van Stolk, 2007). Em locais como, por exemplo, o Reino Unido, tal política é concebida
Em qualquer dos estabelecimentos de ensino, os pais interessados inscreviam os seus filhos como candidatos. Depois, quando era feita a seleção, nas escolas era dada prioridade às crianças que já tinham irmãos matriculados no estabelecimento de ensino. As entrevistadas afirmaram que esta prática visava reforçar o ambiente familiar da escola, assim como manter juntas as crianças de uma mesma família. Objetivamente, este e outros critérios de seleção (por exemplo, as crianças candidatas serem filhas de antigos alunos) funcionavam no sentido de manter a homogeneidade social do recrutamento das escolas e a seleção preferencial de certos tipos de famílias.

"Eu acho que uma das coisas que se calhar tem feito os pais procurarem mais esta escola é porque a maioria os alunos que está cá são filhos de antigos alunos. Um grande, grande, grande número são filhos de antigos alunos, portanto, eles já conheciam a instituição. E depois, aqueles que não são de antigos alunos, muitos são parentes, ou são amigos." (P1)

"Depois de preencher aquelas vagas, porque ... e acabam por não dar resposta [a todos os interessados em matricular os filhos na escola], fica sempre gente de fora, não é? Antigos alunos ... temos em conta os [antigos] alunos, desde que [tenham sido] ou sejam pais que contribuíram bastante e que realmente a sua postura [na escola] [tenha 
sido] de ajuda, de colaboração, talvez [tenhamos isso] em conta, porque realmente é uma pena muitos alunos, às vezes antigos alunos, ficarem postos de fora, não é? (...) Depois de analisados, depois de serem analisados, porque senão, vamos ver ... vamos imaginar que é uma criança que os pais nunca colaboraram nada, quer em termos de disciplina, quer em termos de trabalhos de escola, quer em termos de acatar as regras [da mesma]. Só o fato de ser antigo aluno não Ihes dá direito de entrar, não é? Por isso é que estes casos, às vezes, terão de ser analisados. Se realmente eram pais que trouxeram valores, se eram pais que colaboraram com o professor, se colaboraram com [a escola], (...) aí sim." (D2)

As duas organizações desenvolveram, pois, critérios de seleção que lhes permitiam efetuar a escolha, de um modo alegadamente "justo", dos alunos e famílias que estivessem de acordo com a sua conceção do que era o público desejável. A escola 2 afirmava mesmo, explicitamente, no terceiro critério, que daria prioridade a filhos de antigos alunos, desde que estes tivessem colaborado com a escola, uma expressão suficientemente ambígua para permitir gerir as admissões consoante os interesses da instituição.

\section{Conclusão}

A principal conclusão a que chegamos no presente estudo é que, em contextos em que as famílias podem optar (mesmo que condicionadamente, como é o caso de Portugal) pela escola onde irão matricular os seus filhos, as escolas não agem necessariamente enquanto atores de mercado, no sentido rigoroso do termo num contexto de mercado concorrencial puro. $\mathrm{Na}$ verdade, quando todas as escolas privadas (que podem, em abstrato, competir entre si por alunos, assim como com as escolas públicas) são objeto de um excesso de procura, não sentem necessidade de adotar mecanismos de marketing nem estratégias ostensivamente agressivas para ganharem vantagem sobre os potenciais concorrentes. Optam, pelo contrário, preferencialmente, por, através da diferenciação e de alguma promoção informal, selecionar, de entre a multidão de candidatos, aqueles que mais se ajustam à sua filosofia e imagem de marca, isto é, são as escolas que selecionam as famílias e não estas que selecionam a escola (Barroso, 2003).

No nosso estudo, o processo usado pelas escolas para concretizar este objetivo foi o da definição de um perfil preferencial de aluno, que era desenhado estrategicamente para cumprir tal objetivo, representando uma forma encoberta de seleção social. Não sendo uma forma ostensiva de seleção, a política do perfil preferencial preenche três funções latentes vitais que permitem a formatação pró-ativa do corpo discente por parte da organização: (1) legitima as escolhas feitas pela escola, atribuindo-Ihes uma aparência de "objetividade" e "imparcialidade", isto é, evitando a manifestação explícita de preferências por certos alunos e ajudando assim, de certa forma, a diluir os potenciais conflitos com as famílias cujos filhos, candidatos ao ingresso, não tenham sido admitidos; (2) permite, simultaneamente, manter a "pureza" da composição sociocultural do corpo discente, ao assegurar que os futuros alunos sejam recrutados nos meios socioeconómicos de onde os anteriores são provenientes e (3) por fim, à semelhança das cadeias comerciais que apostam na utilização dos cartões de cliente, funciona como mecanismo eficaz de fidelização da clientela atual, procurando evitar que esta seja atraída por outras escolas e garantir que escolherá, provavelmente, o mesmo estabelecimento de ensino, quando vier a ter filhos em idade escolar.

A opção das escolas pela recolha informal de informação sobre as famílias, em detrimento da utilização do marketing explícito, também pode ser entendida no mesmo sentido. Como sublinharam Bagley et al. (1996), a aquisição informal de feedback pelas escolas permite-Ihes construir a sua própria versão do que são os verdadeiros desejos do "mercado". Contudo, esta recolha informal de informação caracteriza-se pelo enviesamento, tornando possível dar-se mais crédito às perspetivas que são mais consonantes com o que a escola pensa; e pela desigualdade, no sentido em que tal abordagem ad hoc permite privilegiar os pontos de vista de alguns pais em detrimento dos de outros. Na verdade, este tipo de recolha ad hoc de informação, pela sua natureza informal, é seletivo e tal seletividade pode ser entendida como útil pelas escolas, pois estas podem preferir, intencionalmente, escutar mais os pontos de vista de uns pais do que os de outros. Num contexto em que a procura é claramente superior à oferta, é muito possível que tal aconteça.

Pelas razões acima expostas, na admissão de alunos, havendo excesso de candidatos, as escolas por nós estudadas não utilizaram processos aleatórios, mas antes mecanismos de seleção baseados em critérios por elas considerados prioritários. Não deixa de ser significativo verificar, pois, que quando a escolha das famílias não corresponde ao que as escolas pretendem, estas, embora doutrinariamente se reclamem de uma filosofia de mercado livre, podem acabar por introduzir critérios que condicionam a "liberdade" de escolha das famílias candidatas. Em suma, se as famílias escolhem as escolas, estas também podem escolher, mesmo que por processos aparentemente legítimos e objetivos, as famílias que virão a acolher.

As ideias que aqui discutimos são, naturalmente, decorrentes de um estudo empírico bastante circunscrito, envolvendo apenas duas escolas e um pequeno conjunto de entrevistados, pelo que 
sublinhamos a natureza exploratória do mesmo e a ilegitimidade de quaisquer generalizações que possam a partir dele ser realizadas. Mesmo assim, pensamos ter identificado pistas de trabalho úteis que poderão ser desenvolvidas em pesquisas futuras, com desenhos de pesquisa mais alargados e empiricamente mais sustentados.

\section{Notas}

1 Por razões de preservação da confidencialidade, apresentamos estes dados de forma aproximada em vez de fornecer os dados exatos. Julgamos que esta informação é suficiente para construir uma ideia de algumas características essenciais destes estabelecimentos de ensino, sem que a identidade das escolas e das participantes seja revelada, por via indireta.

\section{Referências bibliográficas}

ABRANTES, P. e M. L. Quaresma (2013), "Schools for the Elite, Schools for the Poor: The Same Educational System, Contrasting Socialization Environments", Italian Journal of Sociology of Education, 5 (2), pp. 133-159.

AFONSO, A. (2002), "O neoliberalismo educacional mitigado numa década de governação social-democrata", in L. Lima e A. Afonso (orgs.), Reformas da educação pública: democratização, modernização, neoliberalismo, Porto, Afrontamento, pp. 33-59.

BAGLEY, C.; P. Woods e R. Glatter (1996), "Scanning the Market: School Strategies for Discovering Parental Perspectives", Educational Management Administration \& Leadership, 24 (2), pp. 125-138.

BANACH, W. J. (2001), The ABC of School Marketing, Boston, Scarecrow Education.

BARROSO, J. (2003), "Regulação e desregulação nas políticas educativas: tendências emergentes em estudos de educação comparada", in J. Barroso (org.), A escola pública: regulação, desregulação, privatização, Lisboa, Edições Asa, pp. 79-106.

BARRoSO, J. (2005), Políticas educativas e organização escolar, Lisboa, Universidade Aberta.

COTOVIO, J. (2004), O ensino privado, Lisboa, Universidade Católica Editora.

DALE, R. (1996), "A promoção do mercado educacional e a polarização da educação", Educação, Sociedade \& Culturas, 2, pp. 109-139.

DOLLE, J. R. e A. Newmann (2008), Luck of the Draw? On the Fairness of Charter School Admissions Policies, New York, National Center for the Study of Privatization in Education.
ECKES, S. E. e A. E. Trotter (2007), "Are Charter Schools Using Recruitment Strategies to Increase Student Body Diversity?", Education and Urban Society, 40 (1), pp. 62-90.

ESTEVÃO, C. A. (1998), Redescobrir a escola privada portuguesa como organização, Braga, Universidade do Minho.

ESTEVÃO, C. A. (2000), "O público e o privado em educação: a providenciação pública do privado na educação portuguesa", in J. A. Pacheco (org.), Políticas educativas: o neoliberalismo em educação, Porto, Porto Editora, pp. 137-157.

GLATTER, R.; P. A. Woods e C. Bagley (1997), "Diversity, Differentiation and Hierarchy: School Choice and Parental Preferences", in R. Glatter, P. A. Woods e C. Bagley (eds.), Choice \& Diversity in Schooling, London, Routledge, pp. 7-28.

LAVAL, C. (2003), L'école n'est pas une entreprise: le néo-liberalisme à l'assaut de l'enseignement public, Paris, Éditions de la Découverte.

LEVIN, B. e J. A. Riffel (1997), "School System Responses to External Change: Implications for Parental Choice of Schools", in R. Glatter, P. A. Woods e C. Bagley (eds.), Choice \& Diversity in Schooling, London, Routledge, pp. 44-58.

LIMA, L. e A. Afonso (2002), Reformas da educação pública: democratização, modernização, neoliberalismo, Porto, Edições Afrontamento.

LOCKHART, J. M. (2005), How to Market Your School, Lincoln, NE, iUniverse Inc.

MOLNAR, A. (2006), School Commercialism: From Democratic Ideal to Market Commodity, New York, Routledge/Falmer.

MOORE, M. (2009), "Children Allocated School Places on 'Roll of a Dice'"', The Telegraph, 20 de Fevereiro de 2009. [Disponível em: http://www.telegraph. co.uk/education/educationnews/4737795/Children-allocated-school-places-on-roll-of-a-dice.htm [Última consulta em 06/02/2016].

QUARESMA, M. L. (2014), Entre o herdado, o vivido e o projetado: estudo de caso sobre o sucesso educativo em dois colégios privados frequentados pelas classes dominantes, Porto, Edições Afrontamento.

STASZ, C. e C. Van Stolk, C. (2007), The Use of Lottery Systems in School Admissions, Cambridge, UK, RAND Europe.

WARNER, C. (2009), Promoting Your School, Thousand Oaks, CA, Corwin Press.

WEST, A. e H. Pennel (1997), "Changing Admissions Policies and Practices in Inner London: Implications for Policy and Future Research", in R. Glatter, P. A. Woods e C. Bagley (eds.), Choice \& Diversity in Schooling, London, Routledge, pp. 178-190.

Recebido a 30/05/2016. Aceite para publicação a 18/11/2016.

Jorge Ávila de Lima (jorge.ma.lima@uac.pt). Universidade dos Açores, Faculdade de Ciências Sociais e Humanas, Departamento de Sociologia \& Centro Interdisciplinar de Ciências Sociais (CICS.NOVA.UAçores). R. da Mãe de Deus, 9501-801 Ponta Delgada, Região Autónoma dos Açores.

André Costa Melo (ebi.rabopeixe@azores.gov.pt). Escola Básica e Integrada de Rabo de Peixe, Núcleo de Educação Especial. Rua da Eira, s/n, 9600-140 Rabo de Peixe-Ribeira Grande, Região Autónoma dos Açores. 